\title{
Encouraging Experiential Skill Through Self- Learning Approach: A Case Study of Fieldwork Program
}

\author{
$1^{\text {st }}$ Idris \\ Universitas Negeri Malang \\ Malang, Indonesia \\ idris.fis@um.ac.id
}

\author{
$2^{\text {nd }}$ Bayu Kurniawan \\ Universitas Negeri Malang \\ Malang, Indonesia \\ bayu.kurniawan.fis@um.ac.id
}

\author{
$3^{\text {rd }}$ Agus Purnomo \\ Universitas Negeri Malang \\ Malang, Indonesia \\ agus.purnomo.fis@um.ac.id
}

\begin{abstract}
Self-learning approach becomes one of the learning models that have a significant role in improving students' abilities. Independent efforts of each individual and continuing to increase motivation are challenges that must be solved by students and educators. This study aims to analyze student behavior in outdoor learning through self-directed learning models. Data were collected from 46 students who conducted fieldwork programs and analyzed using statistic descriptive. This study found that self-directed learning provides opportunities for students to develop practical analytical skills in resolving contradictions in understanding between theory in class and practice in the field. In addition, students can also initiate independently to find solutions to the problems they face in the field. New understanding based on experience in the field gives students the ability to be responsible for the tasks assigned.
\end{abstract}

Keywords: experiential skill, self-learning approach, outdoor learning, fieldwork

\section{INTRODUCTION}

The way students get knowledge is not only obtained through learning in a class whose situation is limited by space [1], complicated classroom management [2]-[4] and learning partners that only exist in the classroom such as classmates and teachers [5], but they can also be obtained through learning outside the classroom [6]-[10]. Based on some findings about the effectiveness of learning, learning in class can limit the experience that students want to get [11], [12]. Springer and Collins [13] reveal that formal learning in the classroom is difficult to capture all the components of the situation that exist in the real world, even though in that class interactions between students are created in real terms. James and Williams [14] also explained that classroom learning involving textbooks, lecturers, laboratories, discussion activities, and learning media turned out to be insufficient to develop the concept of understanding students who are very close to the reality of life.

Modern learning does not only prepare students to learn concepts and theories about the world, but in real terms students must also be directed to learn independently about reality and ways to deal with it well [15], [16]. One learning that provides experience, is more dynamic, and meaningful is by learning directly into the field or learning with the community directly or commonly referred to as outdoor education [10], [12], [17]-[20]. By conducting direct learning into the community, students will see, observe, and interact directly with various social realities and phenomena. There are many media that can be used as learning resources such as objects [21], [22], environment [9], and also society [8]. They can make observations while examining the culture, values, customs, and so on.

Classroom learning is a reinforcement of concepts and theories that students must have. The understanding of students built in the classroom is expected to be able to be applied to real life in the community. Problems that arise, in practice, often the theories and concepts in the class differ greatly from the reality faced by the students. The response of students in dealing with this phenomenon is clearly different. Some of them are critically and creatively able to easily handle this. However, not a few of them are very difficult to adjust in a truly new environment and beyond the concepts learned in the classroom such as applying the concepts of research methods and how to conduct interviews. Often the instruments and materials that have been prepared in advance are very different from the objects being studied in the classroom.

The field work program is a medium provided to bridge and train students in implementing theoretical concepts in the classroom with real phenomena that exist in society. In this program, they are directed to make observations while 
in the 2019 field work program (KKL III) where the program

conducting research on a topic that has been prepared in advance. This paper aims to capture how the process of implementing the program is carried out and at the same time provide a description of the behavior of students in the program outside the class.

\section{METHOD}

This research used quantitative methods. Data were collected from 46 students who joined fieldwork in Krisik Village, Blitar Regency. Field work is one of the compulsory courses that must be taken by students. In this program, students were divided into 7 groups with the topic of field research "Identifying the Life Pattern of the Krisik Society based on the perspective of social science". The group received different study themes including land use and disaster, myths, population and harmony, livelihoods and economic activities, social welfare, community entertainment, and village education management. Collecting data used a google form instrument that is distributed to all students who take part in the study. There are 2 types of instruments used including instruments in the class (pre fieldwork) and instruments outside the class (fieldwork). Furthermore, the data is processed using SPSS 23 and analyzed using descriptive statistics.

\section{RESULTS AND DISCUSSION}

\section{A. Field Work Program}

Field work is one of the compulsory courses with a load of 3 credits which must be taken by students three times during the study (KKL I, II, and III). Activities in this field work program are divided into two parts. First, this program is carried out in class by providing theories and concepts about the basics of research. Second, the implementation of programs outside the classroom includes conducting simple research by sending students directly to the field to conduct research. Finally, students prepare academic reports related to the research that has been carried out. All processes for implementing the program are under the direction and supervision of lecturers.

This field work program provides opportunities and opportunities for students to determine learning topics independently in the field related to research method material. They determine research topics, make proposals, determine the research approach to be used, make instruments, and compile reports independently with the group. Students are asked to do all the tasks independently without intervention from the supervisor. Supervisors only provide direction and consultation if needed.

\section{B. Respondent characteristic}

Respondents involved in this study included all students from the Social Sciences Education Program, Faculty of Social Sciences, Universitas Negeri Malang who participated was held in the Krisik Village of Blitar Regency. The characteristics of respondents can be seen in the following figure.

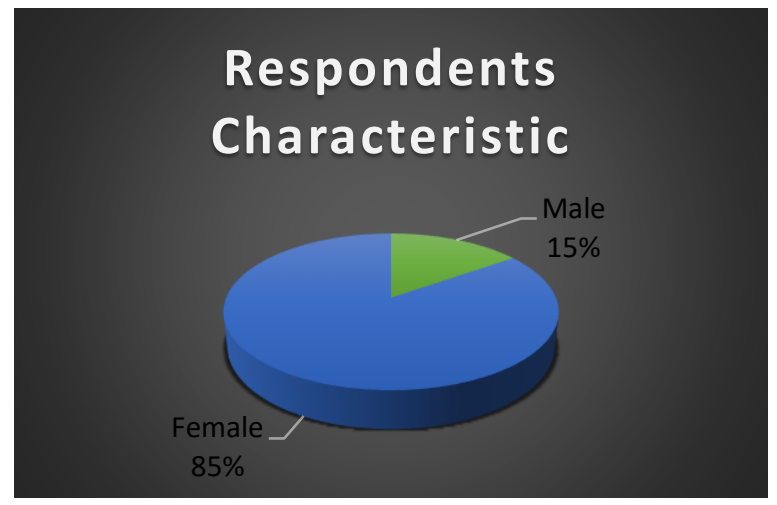

Fig 1. Respondent Characteristic

Figure 1 describes the characteristics of respondents consisting of 7 male students and 39 female students with a percentage ratio of $15 \%$ of men compared to $85 \%$ of women. Based on this number it can be concluded that the respondents in this study were dominated by female respondents. Thus, this also means that students involved in the fieldwork program are dominated by female students with a significant percentage.

\section{Conceptual Understanding}

To see the effectiveness of classroom learning, before students run a field work, evaluation needs to be made regarding the extent of their understanding of the research theories and concepts that have been studied in the classroom. Based on data from the instruments distributed to them before the implementation of the fieldwork, the evaluation results can be seen in the chart as follows.

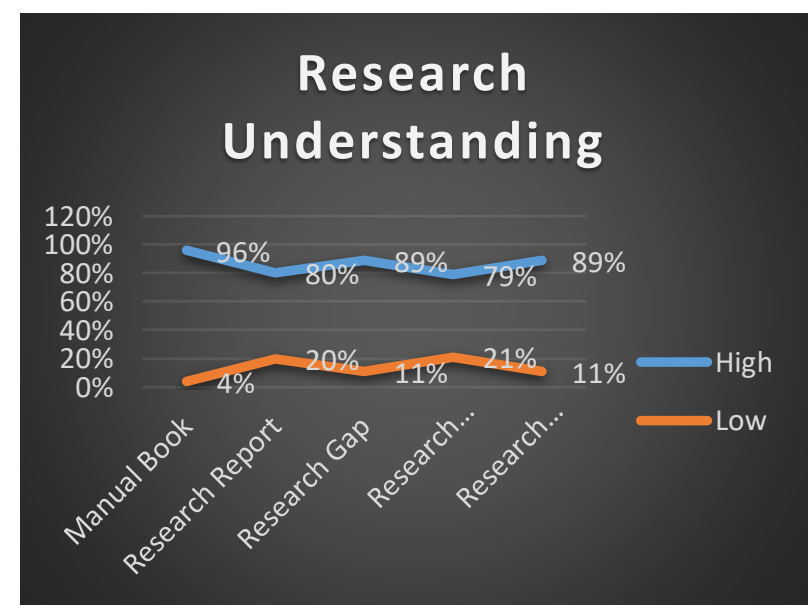

Fig 2. Research Understanding 


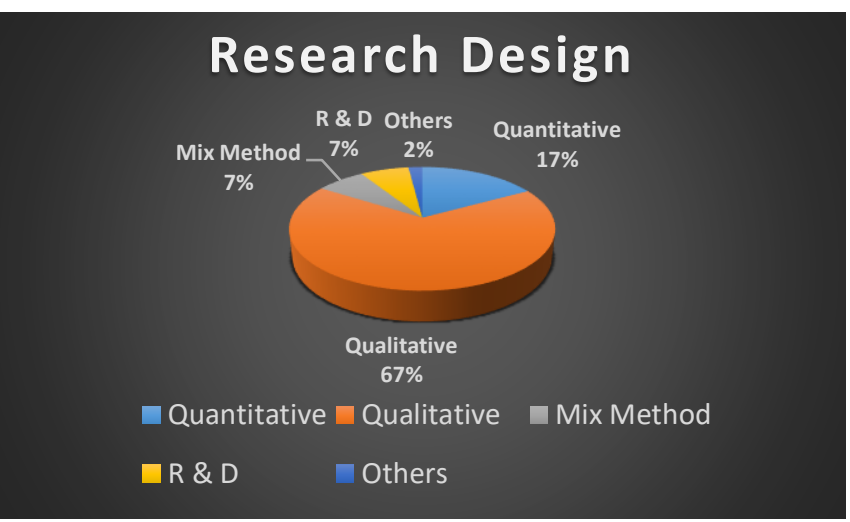

Fig 3. Research Design

\section{Practical Implication}

In accordance with the objectives of the fieldwork program to bridge student understanding in theory and practice, the practical implications of the implementation process outside the classroom are very important to consider as an evaluation of the learning outcomes in the classroom. To take a closer look at the extent to which concepts have been developed in the class are relevant and accurate at the time in the field, it is necessary to evaluate the knowledge gap of students and at the same time require an assessment of new understandings based on initiatives to solve problems outside the class. In addition, how important student behavior in the field process is also seen as assuming new values that are not obtained in the classroom.

\section{E. Gap of Understanding}

Gap of Understanding is a gap in student knowledge of what has been learned in the classroom and it is not found outside the classroom. Students need to adapt and initiate every problem faced in the field. Gap of understanding can also be interpreted as a difference in student understanding of theory and field practice. The gap of understanding found in the implementation of the fieldwork can be seen in detail in Figure 4 as follows.

Students' gap of understanding related to research instruments is still very high with a percentage level of $83 \%$ for students who feel confused how to apply the research instruments that have been made while in the field and there are only $17 \%$ of students who are fully prepared and very familiar with what must be done in the field. The percentage that is not much different can also be seen in the understanding of data collection techniques and job descriptions, both of which have a gap of understanding in a row of $89 \%$ and $80 \%$ respectively. On the contrary, there are only $11 \%$ and $20 \%$ of students who have no difficulty in understanding the data collection techniques and job descriptions of each. Surprisingly, with regard to fieldwork problems, as if they knew that there would be many problems 
obtained by students after the fieldwork program. Figure 5 is the percentage data of student behavior regarding this matter.

The figure explains that the level of student behavior related to communication skills with other people is quite high at $73 \%$ compared to those who do not have communication skills by $28 \%$. Likewise, religious behavior and student initiative attitudes are at a high level with $74 \%$. Meanwhile, caring for the environment is at the above level with $78 \%$. In addition, attitude occupies the highest position in the student behavior section in the field with a percentage reaching $98 \%$. In contrast, the attitudes or behavior of students who are in low positions are leadership, nervous, problem solver, and team work with a percentage of $56 \%, 57 \%, 57 \%$, and $59 \%$ respectively. This means that from the attitudes and behavior of students who take fieldwork programs while in the field they are well-behaved, communicate politely and politely, care for the environment, maintain their religious rituals, and are responsive to having initiations in solving problems that arise during the field. On the contrary, from all their attitudes and behaviors in the field, they are still nervous about dealing with the community directly, their leadership spirit is low, and they have a little problem with their team work.

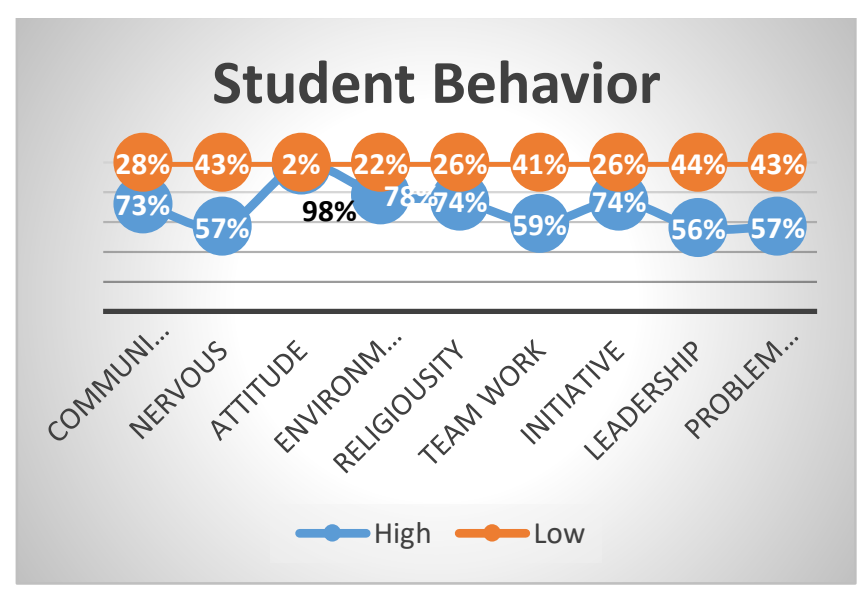

Fig 5. Student behavior

In general, it relates to the existence of a significant understanding gap in some items such as research instruments, collecting data techniques, and difficulties in understanding the job discription of each student while in the field, clarified the importance of field studies regularly during the learning process. In addition, seeing the behavior of students who can learn many things in the real world also provides very significant support in the implementation of fieldwork as a program that is needed for students to continue to process based on the worldview in which they live and will face them in the future. the student behavior. Other behaviors such as religiosity, caring for the environment, initiative, and being a solution to problems faced by themselves or those faced by groups also become important stings in relation to the values that can be 
[9] A. L. McGowan, "Impact of one-semester outdoor education programs on adolescent perceptions of self-authorship," J. Exp. Educ., vol. 39, no. 4, pp. 386-411, 2016.

The Field work program, in general, can be a bridge to the breakup of the world of concepts with reality and can be a broad school for students to learn many things from the various sources of life they face in the field. Students' understanding gaps or gaps they find in the field are a source of new knowledge for them to understand and try to find solutions to all the problems they find. In addition, they not only try to implement concepts or theories in the classroom, but they also learn to behave and act in a good and accurate manner in accordance with the conditions in the field. Learning to communicate well with the community, having the spirit of helping and being loyal to friends, paying attention to cleanliness and the environment, remembering and carrying out religious orders, and having initiations to solve every problem that arises are a very urgent behavior for students.

[10] K. Paisley, N. Furman, J. Sibthorp, and J. Gookin, "Student learning in outdoor education: A case study from the national outdoor leadership school," J. Experintal Educ., vol. 30, no. 3, pp. 201-222, 2008.

[11] K. S. Lekies, G. Yost, and J. Rode, "Urban youth' s experiences of nature: Implications for outdoor adventure recreation," J. Outdoor Recreat. Tour., vol. 9, no. 1, pp. 1-10, 2015.

[12] D. Towers and J. Lynch, "What kind of outdoor educator do you want to become? Trying something different in outdoor studies in higher education," J. Hosp. Leis. Sport Tour. Educ., vol. 21, pp. 117-121, 2017.

[13] S. Springer and L. Collins, "Interacting inside and outside of the language classroom," Lang. Teach. Res., vol. 12, no. 1, pp. 39-60, 2008.

[14] J. K. James and T. Williams, "School-Based Experiental Outdoor Education: A Neglected Necessity," J. Exp. Educ., vol. 40, no. 1, pp. 58-71, 2017.

[15] S. Blenkinsop, J. Telford, and M. Morse, "A surprising discovery: Five pedagogical skills outdoor and experiential educators might offer more mainstream educators in this time of change," $J$. Adventure Educ. Outdoor Learn., vol. 16, no. 4, pp. 346-358, Oct. 2016

\section{REFERENCES}

[1] T. Voss, W. Wagner, U. Klusmann, U. Trautwein, and M. Kunter, "Changes in beginning teachers' classroom management knowledge and emotional exhaustion during the induction phase," Contemp. Educ. Psychol., vol. 51, pp. 170-184, 2017.

[2] R. P. Chaplain, "Stress and psychological distress among trainee secondary teachers in England," Educ. Psychol., vol. 28, no. 2, pp. 195-209, 2008.

[3] C. J. McCarthy, S. Lineback, and J. Reiser, Teacher stress, emotion and classroom management. In E. T. Emmer \& E. J. Sabornie (Eds.), Handbook of classroom management. New York: Routledge, 2015.

[4] J. Schmidt, U. Klusmann, O. Lüdtke, J. Möller, and M. Kunter, "What makes good and bad days for beginning teachers? A diary study on daily uplifts and hassles," Contemp. Educ. Psychol., vol. 48, pp. 85-97, 2017.

[5] A. Brantley, "Learning Outside the Classroom," Phil Delta Kappan, vol. 98, no. 8, pp. 70-75, 2014.

[6] S. Beames, P. J. Higgins, and N. Robbie, Learning Outside The Classroom: Theory and Guidelines for Practice. New York: Routledge, 2012.

[7] D. S. Berman and J. Davis-Berman, "Positive psychology and outdoor education," J. Exp. Educ., vol. 28, no. 1, pp. 17-24, 2005.

[8] B. Daniel, AJ. Bobilya, KR. Kalisch, and LH. McAvoy, "Autonomous student experiences in outdoor and adventure education," J. Exp. Educ., vol. 37, no. 1, pp. 4-17, 2014.

[16] B. Hyndman and L. Mahony, "Developing creativity through outdoor physical activities: a qualitative exploration of contrasting school equipment provisions," J. Adventure Educ. Outdoor Learn., vol. 18, no. 3, pp. 242-256, Jul. 2018.

[17] K. Gilbertson, T. Bates, T. McLaughlin, and A. Ewert, Outdoor education: Methods and strategies. USA: Human Kinetics; 2006.

[18] S. Ho, "The purposes outdoor education does, could and should serve in Singapore," J. Adventure Educ. Outdoor Learn., vol. 14, no. 2, pp. 153-171, 2014

[19] B. Wattchow and M. Brown, A pedagogy of place: Outdoor education for a changing world. Australia: Monash University Publishing, 2011.

[20] I. R. Williams, L. M. Rose, C. A. Olsson, G. C. Patton, and N. B. Allen, "The impact of outdoor youth programs on positive adolescent development: Study protocol for a controlled crossover trial," Int. J. Educ. Res., vol. 87, pp. 22-35, 2018.

[21] G. Bento and G. Dias, "The importance of outdoor play for young children's healthy development," Porto Biomed. J., vol. 2, no. 5, pp. 157-160, 2017.

[22] J. White, Playing and Learning Outdoors: Making provision for high quality experiences in the outdoor environment with children 3-7. New York: Routledge, 2013. 